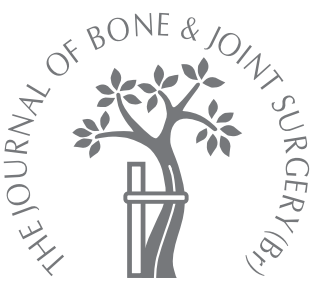

\title{
Total hip replacement in patients with multiple epiphyseal dysplasia with a mean follow-up of 15 years and survival analysis
}

\section{R. Ramaswamy, Y. Kosashvili, H. Cameron \\ From Holland Orthopaedic and Arthritic Centre, Toronto, Ontario, Canada}

R. Ramaswamy, MSc, FRCS(Tr \& Orth), Clinical Fellow in Lower Limb Joint Reconstruction 44 Parcwern Road, Sketty, Swansea SA2 0SF, UK.

- Y. Kosashvili, MD, MHA, Orthopaedic Surgeon Orthopaedic Department Division of Arthroplasty, Assaf Harofeh Hospital, Zerrifin, 70300 Israel.

H. Cameron, MD, FRCSC, Orthopaedic Surgeon, Specialist in Adult hip and Knee Arthroplasty and Reconstruction Holland Orthopaedic and Arthritic Centre, 43 Wellesley Street, East Toronto, Ontario M4Y 1H1, Canada.

Correspondence should be sent to Dr Y. Kosashvili; e-mail: yonasofi@gmail.com

(C)2010 British Editorial Society of Bone and Joint Surgery doi:10.1302/0301-620X.92B4. $22897 \$ 2.00$

$J$ Bone Joint Surg [Br] 2010;92-B:489-95. Received 1 June 2009; Accepted after revision 15 December 2009

The hip joint is commonly involved in multiple epiphyseal dysplasia and patients may require total hip replacement before the age of $\mathbf{3 0}$ years.

We retrospectively reviewed nine patients (16 hips) from four families. The diagnosis of multiple epiphyseal dysplasia was based on a family history, genetic counselling, clinical features and radiological findings. The mean age at surgery was 32 years (17 to 63), with a mean follow-up of 15.9 years (5.5 to 24 ).

Of the 16 hips, ten required revision at a mean of 12.5 years (5 to 15) consisting of complete revision of the acetabular component in three hips and isolated exchange of the liner in seven. No femoral component has loosened or required revision during the period of follow-up.

With revision for any reason, the 15 -year survival was only $11.4 \%$ (95\% confidence interval 1.4 to 21.4). However, when considering revision of the acetabular shell in isolation the survival at ten years was $93.7 \%$ (95\% confidence interval 87.7 to 99.7 ), reducing to $76.7 \%$ (95\% confidence interval 87.7 to 98.7 ) at 15 and 20 years, respectively.

Multiple epiphyseal dysplasia (MED) is one of the more common skeletal dysplasias. ${ }^{1}$ It is characterised by abnormal maturation of the epiphyses, affecting the hips, knees and ankles to a larger extent than the shoulders, elbows and wrists. It was first described by Fairbank, ${ }^{2}$ is transmitted either as an autosomal dominant with variable penetrance, or less frequently as an autosomal recessive condition. Two autosomal dominant phenotypes, a severe form (Fairbank's) and a milder form (Ribbing's) have been reported. The genetic abnormalities are due to mutations in the gene coding for cartilage oligometric matrix protein and the $\alpha 1$, 2, 3 polypeptide chain of type IX collagen. ${ }^{1}$ These mutations result in abnormal enchondral ossification, which in turn forms poorquality cartilage which is unable to withstand normal cyclical loads. The autosomal recessive form is related to defects in the gene coding for diastrophic dysplasia sulphate transporter, which is required for synthesis of sulphated proteoglycans in cartilage. ${ }^{3,4}$ Most phenotypes due to recessive mutations result in bilateral club foot, multiple epiphyseal dysplasia and a double-layered patella. ${ }^{4}$

Patients with multiple epiphyseal dysplasia are characterised by mild asymmetric short stature, with short limbs relative to their trunk, short stubby digits, early-onset osteoarthritis involving mainly the weight-bearing joints, and a waddling gait. ${ }^{3,5}$ Their sexual development, intelligence and lifespan are normal. ${ }^{1,5}$

Coxarthrosis secondary to multiple epiphyseal dysplasia is usually bilateral and often presents with a symmetrical involvement. ${ }^{1,3,6}$ The reconstructive challenges in these patients are magnified because of atypical geometry of the hip in both the femur and the acetabulum. ${ }^{7}$ The femoral anomalies include an expanded metaphysis, a narrow isthmus and a varus femoral neck-shaft angle, as opposed to a valgus neckshaft angle observed in developmental dysplasia of the hip (Fig. 1). The acetabulum is typically dysplastic, with deficiency of the dome and anterior wall predisposing to various degrees of proximal femoral displacement (Fig. 1).

Patients with multiple epiphyseal dysplasia may require total hip replacement (THR) as early as the third decade of life. ${ }^{8,9}$ Two recent studies have reported encouraging results at early follow-up, ${ }^{9,10}$ but the literature regarding the long-term results of THR in these patients is limited. Such information is imperative for young patients undergoing THR, as they are likely to face revision during their normal lifespan. Information on the outcome enables both the surgeon and the patient to have better appreciation of the functional benefits, potential complications, implant survival and need 


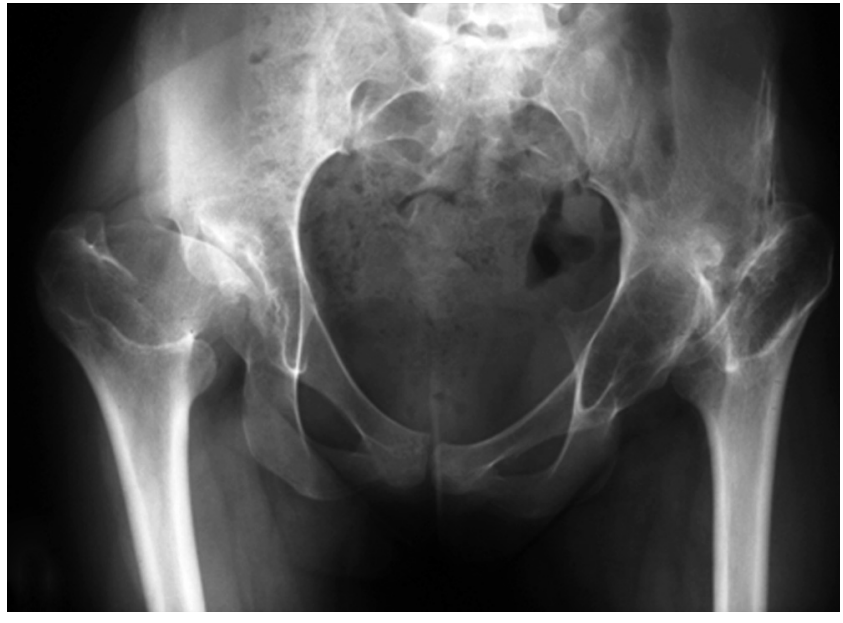

Fig. 1

Radiological features of multiple epiphyseal dysplasia affecting the hips bilaterally.

for future revision. We describe the long-term clinical outcome of THR in a series of patients with this abnormality.

\section{Patients and Methods}

Between July 1985 and November 2003 nine patients (16 hips) with multiple epiphyseal dysplasia underwent a THR for symptomatic osteoarthritis of the hip. They came from four families whose family trees are shown in Figure 2. The diagnosis was based on a family history, genetic counselling performed only for the offspring in each family, the clinical and radiological features (Table I). The indication for THR was deterioration in mobility to pain, which also substantially interfered with activities of daily living.

There were five men and four women. Their mean height was $154.1 \mathrm{~cm}$ (143 to 160) and mean weight $61.6 \mathrm{~kg}$ (50.4 to 72 ). Their mean age at surgery was 32 years ( 17 to $63)$. Their details and that of the operation and implants are shown in Table II. In 12 hips the acetabular dysplasia was graded, according to the classification of Hartofilakidis et $\mathrm{al},{ }^{11}$ as type 2 (low dislocation) and in the remaining four as type 1 (dysplasia). In 13 of the 16 hips various features of the abnormal femoral geometry were present.

All procedures were performed by the senior surgeon (HC) through a transgluteal approach. Seven patients had bilateral THRs; two had unilateral procedures and are awaiting operation on the other side.

An S-ROM femoral component (Depuy/Johnson and Johnson, Warsaw, Indiana) was used in 13 hips. The other three had cemented femoral implants (Table II). The S-ROM femoral stem is a modular cementless prosthesis made of titanium alloy (6 A1 4V Ti). It has thin, sharp flutes distally that are designed to engage the endosteal cortex to provide rotational stability. The stem is split distally to reduce the bending stiffness and the mismatch of the modulus of elasticity between the stem and bone. ${ }^{12}$ The
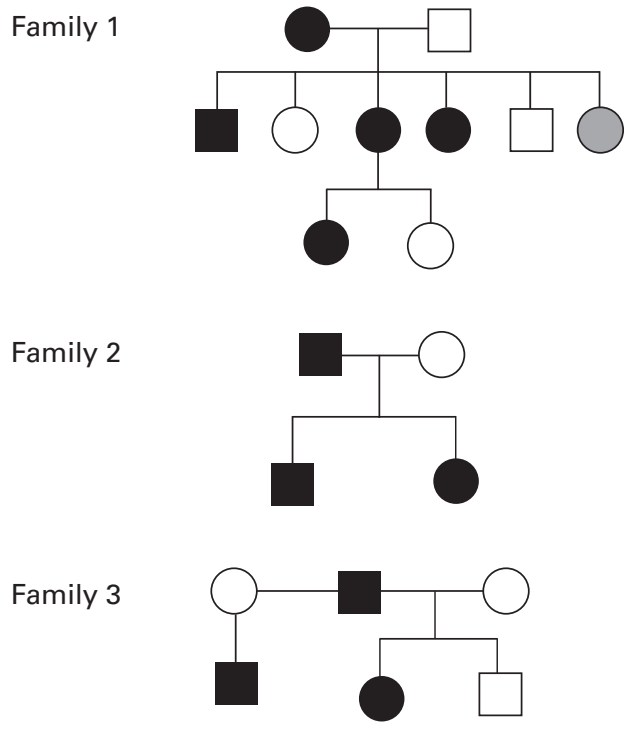

Family 4
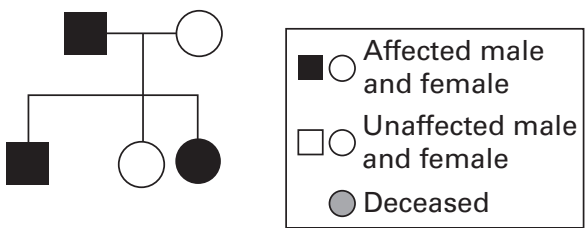

Fig. 2

The family histories of those involved in the study.

proximal sleeve couples to the stem by means of a Morse taper and is porous coated with an irregular roughened texture. It can be coupled to the stem in any position of version.

All the acetabular components were cementless, secured by screws (Table II) and did not require mechanical buttressing with allografts or augments. The bearing combinations in all hips were metal on ultra-high molecular weight polyethylene (UHMWPE). All patients received $1 \mathrm{~g}$ cefazolin intravenously one hour prior to the skin incision, followed by two post-operative doses. Oral coumadin was used in all patients for thromboprophylaxis. Patients were mobilised on the first post-operative day but were kept on touch weight-bearing for six weeks, with a subsequent gradual return to full weight-bearing over a period of two weeks.

Clinical and radiological data were collected before operation and at six weeks, six months, one year, and annually thereafter. Clinical evaluations included Merle d'Aubigné and Postel hip scores. ${ }^{13}$

Routine radiographs consisting of an anteroposterior (AP) view of the pelvis as well as an AP and lateral view of the affected hip, were taken to evaluate pre-operative acetabular dysplasia, which was present in all patients. The initial six-week post-operative radiographs served as the baseline against which all subsequent views were compared. The radiographs were evaluated by two of the 
Table I. Typical features of multiple epiphyseal dysplasia in each patient

\begin{tabular}{|c|c|c|c|c|c|c|c|}
\hline Patient & $\begin{array}{l}\text { Genetic } \\
\text { counselling }\end{array}$ & $\begin{array}{l}\text { Positive family } \\
\text { history }\end{array}$ & $\begin{array}{l}\text { Typical radiological } \\
\text { findings }\end{array}$ & $\begin{array}{l}\text { Asymmetrical short } \\
\text { stature }\end{array}$ & $\begin{array}{l}\text { Multiple joint } \\
\text { involvement }^{*}\end{array}$ & Short digits & Club feet \\
\hline 1 & No & Yes & Yes & Yes & Yes & No & No \\
\hline 2 & Yes & Yes & Yes & Yes & Yes & Yes & Yes \\
\hline 3 & Yes & Yes & Yes & Yes & Yes & No & No \\
\hline 4 & Yes & Yes & Yes & Yes & Yes & Yes & No \\
\hline 5 & No & Yes & Yes & Yes & Yes & No & No \\
\hline 6 & Yes & Yes & Yes & Yes & Yes & Yes & No \\
\hline 7 & Yes & Yes & Yes & Yes & Yes & Yes & Yes \\
\hline 8 & No & Yes & Yes & Yes & Yes & Yes & No \\
\hline 9 & Yes & Yes & Yes & Yes & Yes & Yes & Yes \\
\hline
\end{tabular}

* involvement of other joints apart from the hip

authors (RR and HC) for loosening of a component and heterotopic ossification, graded according to Brooker's classification. ${ }^{14}$ Fixation of the acetabular component was examined for its migration and for the presence of radiolucent lines. ${ }^{15}$ In each patient the vertical distance of the centre of rotation of the hip from the inter-ischial line and the horizontal distance from the centre of rotation to the ipsilateral teardrop were determined (Fig. 3). Failure of the acetabular component was considered when migration or loosening was observed. Migration was defined as horizontal or vertical movement $>5 \mathrm{~mm}$, and loosening was diagnosed if circumferential radiolucent lines, including in the area around the screws, were demonstrated. ${ }^{15}$

Loosening of the femoral component was defined as progressive subsidence $>3 \mathrm{~mm}$ or a varus-valgus shift $>3^{\circ} .{ }^{16}$ Subsidence was evaluated by measuring the distance from the tip of the greater trochanter to the upper margin of the lateral shoulder of the component, and the distance between the most proximal medial part of the porous-coated surface of the component and the upper border of the lesser trochanter. A femoral component was considered loose when there was a complete radiolucent line surrounding the component both on AP and lateral radiographs. ${ }^{16}$

Statistical analysis. Statistical analysis was performed using the Statistical Package for Social Science (SPSS) software version 15.0 (SPSS Inc., Chicago, Illinois).

We performed survival analyses using the KaplanMeier method and calculated 95\% confidence intervals (CI) for the endpoints. ${ }^{17}$ The first survival analysis regarded revisions performed for aseptic loosening of the components as an endpoint, excluding revisions consisting of exchange of the liner of the acetabular component only. The second survival analysis regarded every hip revision, including both acetabular component revision and liner exchange, as an endpoint.

\section{Results}

The mean follow-up was for 15.9 years (5.5 to 24). None of the patients was lost to follow-up. The Merle d'Aubigné and
Postel hip scores improved from a mean of 6.4 points $(2$ to $10)$ pre-operatively to a mean of 12.5 (10 to 15$)$ at one year after THR, although these scores declined to a mean of 10.6 (7 to 15) at the latest follow-up. The pain component showed the largest mean drop at latest follow-up of 0.8 versus 0.53 both for the range of movement and ability to walk.

In ten of the 16 THRs, revision was required at a mean of 12.5 years (5 to 15 ). For three of these revision of the acetabular component was undertaken for aseptic loosening, and the remaining seven were for exchange of the liner only (Fig. 4). The decision regarding fixation of the acetabular component was based on pre-operative radiographs and intra-operative assessment, which included manual traction and visual determination of bone ingrowth into the periphery of the component. Two of the three acetabular revisions were in the first patient to be included in the study (patient 7, Table II). She had both THRs performed with threaded acetabular devices. She underwent a revision on one side five years after her first THR, and the contralateral hip was revised 14 years after the primary procedure. All acetabular revisions, whether for the liner alone or the complete component, were combined with bone grafting of the respective osteolytic lesions, especially at the ischium and superior pubic ramus. Follow-up radiographs after revision showed non-progressive radiolucent lines around the acetabular component, limited to zones 2 and 3 of DeLee and Charnley ${ }^{18}$ at the latest follow-up of a mean of 7.1 years (3.8 to 18.5 ).

None of the femoral components was revised in any of these patients. There was radiological evidence of spot welding ${ }^{19}$ into all 13 S-ROM femoral components, especially at the superior and inferior margins of the S-ROM sleeve. No radiolucencies were noted around the cemented or the cementless components. No migration of any of the femoral components was noted in the follow-up radiographs. During the acetabular revisions, manual testing of each femoral component excluded the presence of loosening.

Heterotopic ossification was noted in 11 hips and was classified according to Brooker's classification: ${ }^{14}$ four with grade 1, three with grade 2 and four with grade 3 (Table II). 
Table II. Patient demographic and peri-operative data

\begin{tabular}{|c|c|c|c|c|c|c|c|c|c|c|c|c|c|}
\hline $\begin{array}{l}\text { Patient } \\
\text { code }\end{array}$ & $\begin{array}{l}\text { Age at } \\
\text { surgery } \\
\text { (yrs) }\end{array}$ & Height (cm) & $\begin{array}{l}\text { Weight } \\
\text { (kg) }\end{array}$ & BMI $^{*}$ & $\mathrm{DDH}^{\dagger}$ & $\begin{array}{l}\text { Follow-up } \\
\text { (yrs) }\end{array}$ & $\begin{array}{l}\text { Type of } \\
\text { replacement }\end{array}$ & $\begin{array}{l}\text { Acetabular } \\
\text { component } \\
\text { size (mm) }\end{array}$ & $\begin{array}{l}\text { Head } \\
\text { size } \\
(\mathrm{mm})\end{array}$ & $\begin{array}{l}\text { Femoral } \\
\text { stem (mm) }\end{array}$ & $\mathrm{HO}^{\ddagger}$ & $\begin{array}{l}\text { Time to } \\
\text { revision } \\
\text { (yrs) }\end{array}$ & $\begin{array}{l}\text { Type of } \\
\text { revision }\end{array}$ \\
\hline 1 & 63 & 154 & 70 & 31.5 & 1 & 5.8 & Hybrid & 44 & 28 & 13 & Nil & 5.8 & \\
\hline \multicolumn{14}{|l|}{2} \\
\hline L & 17 & 143 & 61 & 26.2 & 2 & 18.0 & Cementless & 39 & 22 & 9 & 3 & 14.0 & $\begin{array}{l}\text { Liner } \\
\text { exchange }\end{array}$ \\
\hline $\mathrm{R}$ & 18 & 143 & 61 & 26.2 & 2 & 17.0 & Cementless & 39 & 22 & 9 & 3 & 12.0 & $\begin{array}{l}\text { Liner } \\
\text { exchange }\end{array}$ \\
\hline \multicolumn{14}{|l|}{3} \\
\hline $\mathrm{L}$ & 35 & 160 & 63 & 24.8 & 2 & 10.0 & Cementless & 42 & 22 & 11 & 2 & 10.0 & \\
\hline $\mathrm{R}$ & 39 & 160 & 63 & 24.8 & 2 & 5.5 & Cementless & 42 & 22 & 11 & 3 & 5.5 & \\
\hline 4 & 19 & 157 & 66 & 27.5 & 1 & 7.5 & Cementless & 60 & 28 & 11 & 1 & 7.5 & \\
\hline \multicolumn{14}{|l|}{5} \\
\hline $\mathrm{L}$ & 42 & 160 & 72 & 32.4 & 2 & 14.0 & Cementless & 63 & 28 & 11 & 1 & 14.0 & \\
\hline $\mathrm{R}$ & 41 & 160 & 72 & 32.4 & 2 & 15.0 & Cementless & 63 & 28 & 11 & 1 & 15.0 & \\
\hline \multicolumn{14}{|l|}{6} \\
\hline $\mathrm{L}$ & 24 & 157 & 68 & 29.0 & 2 & 19.0 & Cementless & 45 & 22 & 11 & 2 & 12.0 & $\begin{array}{l}\text { Liner } \\
\text { exchange }\end{array}$ \\
\hline $\mathrm{R}$ & 25 & 157 & 68 & 29.0 & 2 & 18.0 & Cementless & 45 & 22 & 11 & 1 & 12.0 & $\begin{array}{l}\text { Liner } \\
\text { exchange }\end{array}$ \\
\hline \multicolumn{14}{|l|}{7} \\
\hline$L$ & 25 & 149 & 54 & 19.6 & 2 & 24.0 & Hybrid & 48 & 32 & 11 & 3 & 5.0 & $\begin{array}{l}\text { Acetabulum } \\
\text { only }\end{array}$ \\
\hline $\mathrm{R}$ & 26 & 149 & 54 & 19.6 & 2 & 22.5 & Hybrid & 48 & 32 & 11 & 2 & 13.5 & $\begin{array}{l}\text { Acetabulum } \\
\text { only }\end{array}$ \\
\hline \multicolumn{14}{|l|}{8} \\
\hline $\mathrm{L}$ & 45 & 157 & 57 & 20.5 & 1 & 19.0 & Cementless & 48 & 28 & 13 & Nil & 15.0 & $\begin{array}{l}\text { Liner } \\
\text { exchange }\end{array}$ \\
\hline $\mathrm{R}$ & 46 & 157 & 57 & 20.5 & 1 & 18.0 & Cementless & 48 & 28 & 13 & Nil & 12.5 & $\begin{array}{l}\text { Liner } \\
\text { exchange }\end{array}$ \\
\hline \multicolumn{14}{|l|}{9} \\
\hline$L$ & 23 & 151 & 50 & 16.8 & 2 & 20.8 & Cementless & 42 & 22 & 9 & Nil & 14.5 & $\begin{array}{l}\text { Liner } \\
\text { exchange }\end{array}$ \\
\hline $\mathrm{R}$ & 24 & 151 & 50 & 16.8 & 2 & 20.0 & Cementless & 42 & 22 & 9 & Nil & 14.0 & $\begin{array}{l}\text { Acetabulum } \\
\text { only }\end{array}$ \\
\hline $\begin{array}{l}\text { Mean } \\
\text { (range) }\end{array}$ & $\begin{array}{l}32 \\
\text { (17 to } 53)\end{array}$ & $\begin{array}{l}154.1 \\
)(143 \text { to } 160)\end{array}$ & $\begin{array}{l}61.6 \\
\text { (50 to } 72)\end{array}$ & $\begin{array}{l}24.8 \\
\text { (16.8 to } 32.4)\end{array}$ & & $\begin{array}{l}15.9 \\
(5.5 \text { to } 24.0)\end{array}$ & & & & & & $\begin{array}{l}11.4 \\
(5.0 \text { to } \\
15.0)\end{array}$ & \\
\hline
\end{tabular}

* BMI, body mass index in $\mathrm{kg} . \mathrm{cm}^{2}{ }^{2}{ }^{10}$

$+\mathrm{DDH}$, type of acetabular dysplasia according to Hartofilakidis classification ${ }^{10}$

$\ddagger \mathrm{HO}$, grade of heterotopic ossification according to Brooker's classification ${ }^{12}$

When revision of acetabular components (aseptic loosening) was considered as an endpoint, the ten-year survival of the acetabular and femoral components was $93.7 \%$ (95\% CI, 87.7 to 99.7), while the 15 - and 20-year survivals were both $76.7 \%$ (95\% CI, 64.7 to 88.7 , number at risk: 16 at four years, 15 at five years, 11 at ten years, seven at 15 years, one at 20 years and one at 25 years, (Fig. 5)).

When revision for exchanging the liner or for aseptic loosening of the acetabular component was considered as an endpoint, the overall 10-year survival was $93.7 \%$ (95 CI, 87.7 to 99.7). However, the overall 15 -year survival was only $11.4 \%$ (95\% CI, 1.4 to 21.4 , number at risk: 16 at four years, 13 at six years, 12 at eight years, 11 at ten years, three at 14 years and two at 16 years, (Fig. 6)).

\section{Discussion}

The hip joint is commonly involved in multiple epiphyseal dysplasia, with most patients requiring THR before the age of $30 .^{8}$ Because these patients are younger and have high functional demands, it might be anticipated that they would require repeated reconstructions, given their normal life expectancy. Although recent studies have indicated 


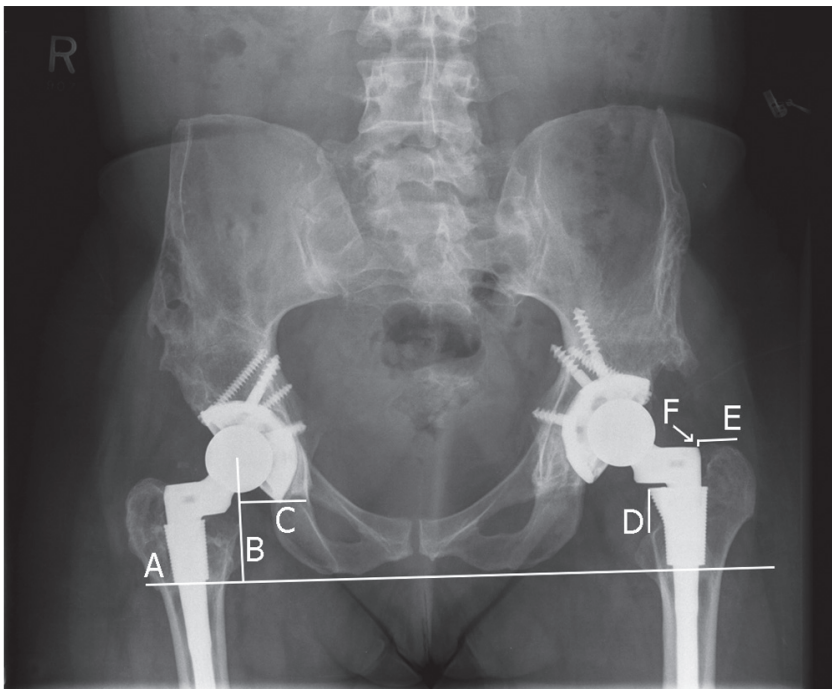

Fig. 3

An annotated post-operative pelvic radiograph showing the measurements used to depict acetabular or femoral migration. Line A, interischial line; line $B$, the vertical height of the hip centre of rotation from the inter-ischial line; line $C$, the medial distance of the centre of rotation from the teardrop; line $D$, the distance between the most proximal medial part of the porous-coated surface of the stem and the upper border of the lesser trochanter; line $\mathrm{E}$, a line from the tip of the greater trochanter parallel to the inter-ischial line; line $F$, the distance from the tip of the greater trochanter and the upper margin of the lateral shoulder of the stem. Stem subsidence was evaluated by measuring the distance from the tip of the greater trochanter to the upper margin of the lateral shoulder of the stem (line F), as well as measuring the distance between the most proximal medial part of the porous-coated surface of the stem and the upper border of the lesser trochanter (line D) and measuring the distance from the centre of rotation to the interischial line (line B).

early promising results, there are no long-term outcomes of THR in those patients in the literature. ${ }^{9,10}$ Our study presents the outcomes of THR at a mean follow-up of 15.9 years (5.5 to 24$)$.

Clinical outcomes following THR in patients with skeletal dysplasias, including multiple epiphyseal dysplasia, spondylo-epiphyseal dysplasia and pseudo-achondroplasia, have been reported to be acceptable in terms of providing pain relief and improving quality of life..$^{9,10,20,21}$ Our patients had improvements in the Merle d'Aubigné and Postel hip scores, but the scores were lower than those after THR in patients with developmental dysplasia reported in the literature. ${ }^{22,23}$ This difference might be attributable to the variable involvement of after joints such as the knee or the ankle in the affected limb.

None of the femoral components in our series required revision. The reason for using an S-ROM cementless femoral component in most of these patients was to address the atypical femoral geometry. ${ }^{7,20,23}$ The modularity between the S-ROM stem and the sleeve allows optimal engagement, both at the diaphysis and at the metaphysis of the femur, which are mismatched in such patients. ${ }^{10,12}$ The long-term fixation of the S-ROM cementless femoral component is based on proximal fixation around the sleeve,

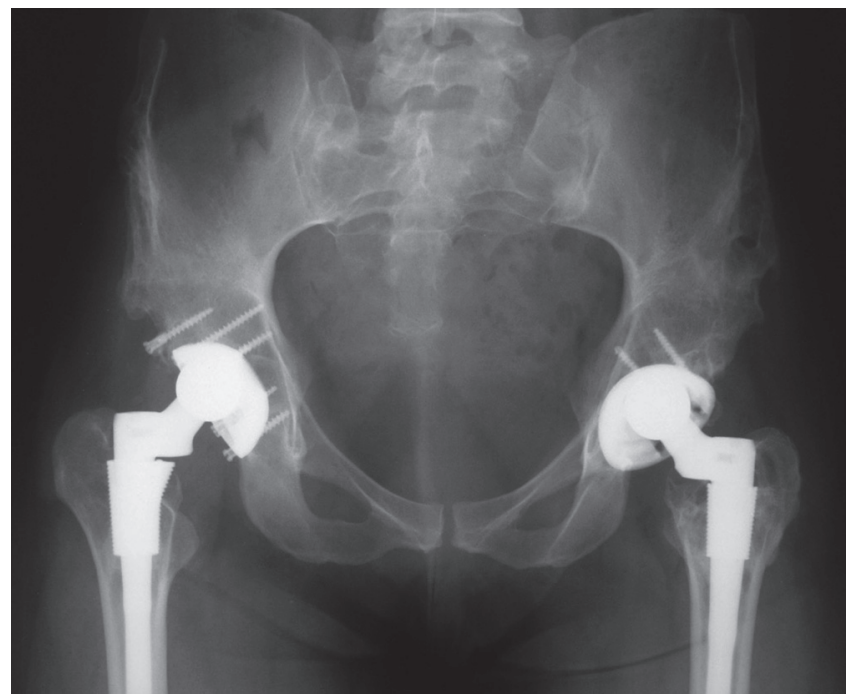

Fig. $4 a$

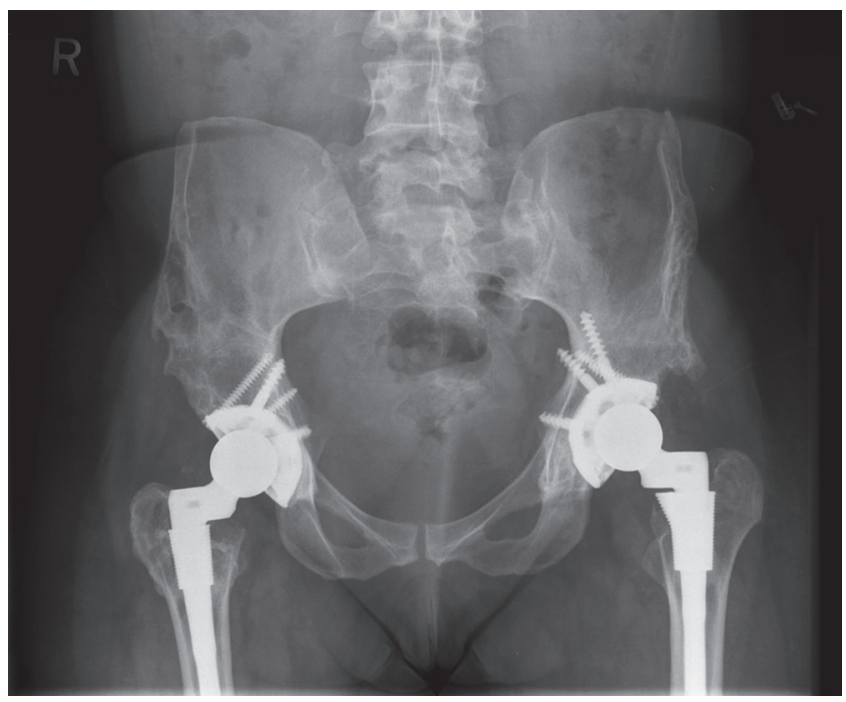

Fig. $4 b$

(A) Severe bilateral polyethylene liner wear in patient 9. (B) The acetabular component was replaced on the left because of damage to the shell whereas only the liner was replaced on the right hip. The liner in this total hip replacement system (Artropore 1, DePuy, Warsaw, Indiana) allows fixation with peripheral screws. Note 'spot welding' around the superior and inferior margins of the S-ROM sleeve.

preserving the diaphysis for future femoral reconstruction if required. An alternative approach to the problem of the narrow isthmus and the need for various degrees of anteversion of the stem in these patients has been described by Pavone et $\mathrm{al}^{9}$ using a cone stem, with successful results in seven patients with multiple epiphyseal dysplasia who underwent bilateral THR with a mean follow-up of 6.1 years. One of the possible disadvantages of using an S-ROM femoral component in patients with smaller stature is the relative length, which may cause anterior impaction due to proximal femoral bowing. Thus, pre-operative templating on 


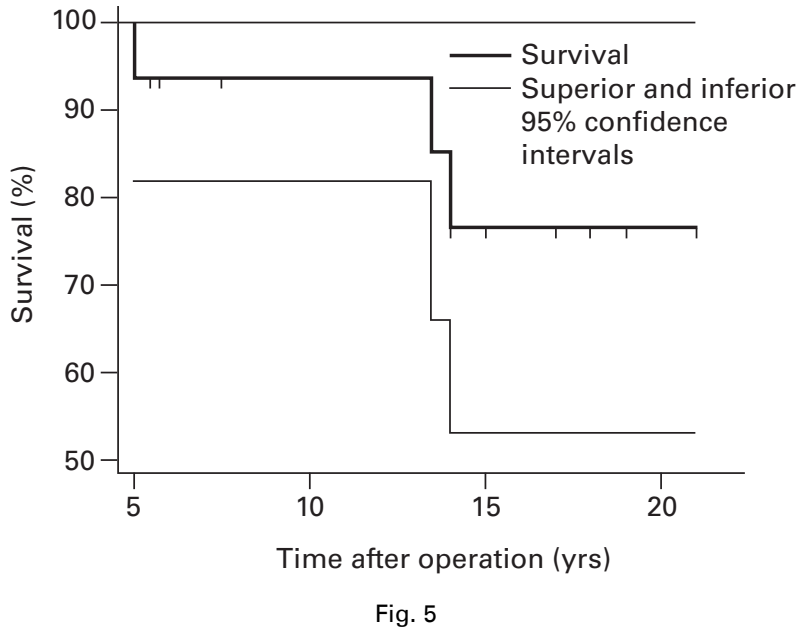

Survival analysis of the primary replacement when aseptic loosening was considered as an endpoint.

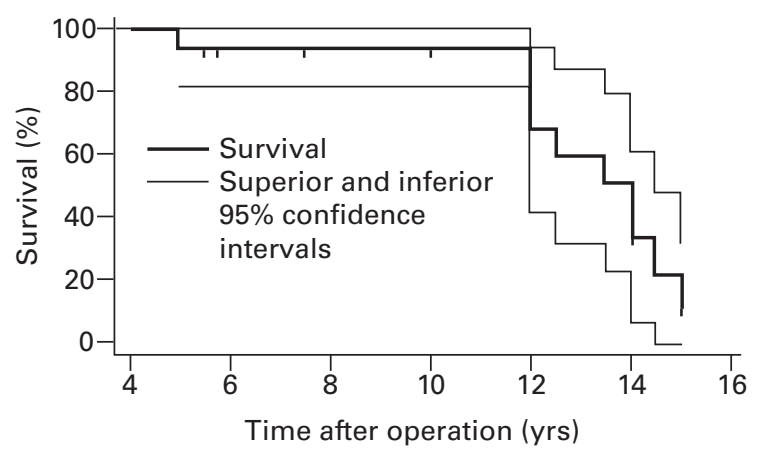

Fig. 6

Survival analysis of the primary total hip replacement with revision for any reason as the endpoint.

both the anteroposterior and lateral radiographs is imperative in order to identify the appropriate entry point for the femoral component. Although not experienced with our patients, if the lateral templating did identify that a problem would occur accomodating the stem, the shorter diaphyseal fitting S-ROM A (DePuy, Warsaw, Indiana) design or custom-made components might be necessary.

The weak link in our series was the acetabular component, with ten of the 16 THRs requiring revision at a mean of 12.5 years, seven of which were isolated revisions of the liner of the acetabular component. The only early aseptic loosening occurred five years post-operatively in a patient with bilateral threaded acetabular components (S-ROM acetabular components, Joint Medical Products Corporation, Stamford, Connecticut). These devices are recognised to have a poor outcome and are no longer in use in North America. ${ }^{12}$ In all, nine of the ten acetabular revisions were performed 12 or more years post-operatively. The rate of revisions consisting of liner exchange in our series was higher than those in a previous series which described an incidence of $31 \%$ due to polyethylene wear in 34 patients with deficient bone stock and small femoral canals. ${ }^{12}$ These excessive rates of liner wear could be related to the fact that, in an attempt to minimise the excision of acetabular host bone, the external diameters of the metal backings of five of the seven isolated liner exchanges were $45 \mathrm{~mm}$ or less, which restricted the liner to a thickness of $4.6 \mathrm{~mm}$. The latest version of the acetabular component allows a polyethylene thickness of $5.2 \mathrm{~mm}$, even in acetabular components as small as $40 \mathrm{~mm}$ in external diameter. In all seven liner exchanges, the shell remained firmly fixed and revision to a larger diameter to accommodate a thicker polyethylene insert would have resulted in loss of native bone. Revision THRs using structural grafting to address such defects carries an increased risk of early loosening. ${ }^{24}$ Instead of using cementless acetabular components in such circumstances, impaction bone grafting with cemented all-polyethylene implants may be preferable, as the technique has shown promising results even in younger patients. ${ }^{25}$

Throughout the follow-up no femoral component required revision, but with most failures occurring between ten and 15 years due to liner wear, a better option might be the adoption of hard-on-hard bearings. ${ }^{26,27}$ If a metal-onpolyethylene bearing is preferred by the surgeon or the patient, then highly cross-linked polyethylene might be advisable, as it has shown better wear properties at seven years. ${ }^{28,29}$

We found a high incidence of heterotopic ossification. This is consistent with studies of other skeletal dysplasias such as achondroplasia and thanatophoric dysplasia, where a higher incidence of heterotopic ossification has also been noted. ${ }^{30,31}$ Although there might be a link between skeletal dysplasia including multiple epiphyseal dysplasia and heterotopic ossification, we are not aware of literature suggesting an underlying mechanism for this association. Despite the fact that we did not find direct morbidity related to heterotopic ossification, routine prophylactic treatment with post-operative radiation or non-steroidal anti-inflammatories in these patients might be helpful. ${ }^{32,33}$

There are several limitations to this study. First, it is retrospective. Second, there was a lack of a dedicated follow-up questionnaire for this condition. The widely used Harris Hip Score was designed for use with a typical patient with arthritis. ${ }^{34}$ However, patients with multiple epiphyseal dysplasia have severe functional limitations due to their multiple joint involvement, resulting in low pre- and postoperative scores. This could be only partly overcome by using Merle d'Aubigné and Postel scores, which the authors found to be more specific in relation to the joint evaluated. At follow-up, review of the patients was not blinded. Because this was not a randomised study, bias and confounders are difficult to control.

With a survival rate exceeding $90 \%$ at ten years, THR is a viable option for patients with multiple epiphyseal dysplasia even at an early age, as it offers substantial pain relief and improvement in quality of life. 
The author or one or more of the authors have received or will receive benefits for personal or professional use from a commercial party related directly or indirectly to the subject of this article.

\section{References}

1. Unger S, Bonafé L, Superti-Furga A. Multiple epiphyseal dysplasia: clinical and radiographic features, differential diagnosis and molecular basis. Best Pract Res Clin Rheumatol 2008;22:19-32.

2. Fairbank T. Dysplasia epiphysealis multiplex. Br J Surg 1947;34:225-32.

3. Lachman RS, Krakow D, Cohn DH, Rimoin DL. MED, COMP, multilayered and NEIN: an overview of multiple epiphyseal dysplasia. Pediatr Radiol 2005;35:116-23.

4. Miyake A, Nishimura G, Futami T, et al. A compound heterozygote of novel and recurrent DTDST mutations results in a novel intermediate phenotype of Desbuquois dysplasia, diastrophic dysplasia, and recessive form of multiple epiphyseal dysplasia. J Hum Genet 2008:53:764-8.

5. Jones KL. Smith's recognizable patterns of human malformation. Fifth ed. Philadelphia: W.B. Saunders Co., 1997:380-1.

6. Sebik A, Sebik F, Kutluay E, Kuyurtar F, Ademoglu Y. The orthopaedic aspects of multiple epiphyseal dysplasia. Int Orthop 1998;22:417-21.

7. Ain MC, Andres BM, Somel DS, Fishkin Z, Frassica FJ. Total hip arthroplasty in skeletal dysplasias: patient selection, preoperative planning, and operative techniques. J Arthroplasty 2004;19:1-7.

8. Treble NJ, Jensen FO, Bankier A, Rogers JG, Cole WG. Development of the hip in multiple epiphyseal dysplasia: natural history and susceptibility to premature osteoarthritis. J Bone Joint Surg [Br] 1990;72-B:1061-4.

9. Pavone V, Costarella L, Privitera V, Sessa G. Bilateral total hip arthroplasty in subjects with multiple epiphyseal dysplasia. J Arthroplasty 2009;24:868-72.

10. Lim SJ, Park YS, Moon YW, et al. Modular cementless total hip arthroplasty for multiple epiphyseal dysplasia. J Arthroplasty 2009;24:77-82.

11. Hartofilakidis G, Stamos K, Karachalios T, Ionnidis TT, Zacharakis N. Congenital hip disease in adults: classification of acetabular deficiencies and operative treatment with acetabuloplasty combined with total hip arthroplasty. J Bone Joint Surg [Am] 1996; 78-A:683-92.

12. Cameron HU, Lee BO, Chou H. Total hip arthroplasty in patients with deficient bone stock and small femoral canals. J Arthroplasty 2003;18:35-40.

13. Merle d'Aubigné R, Postel M. Functional results of hip arthroplasty with acrylic prosthesis. J Bone Joint Surg [Am] 1954;36-A:451-75

14. Brooker AF, Bowerman JW, Robinson RA, Riley LH Jr. Ectopic ossification following total hip replacement. J Bone Joint Surg [Am] 1973;55-A:1629-32.

15. Massin P, Schmidt L, Engh CA. Evaluation of cementless acetabular component migration: an experimental study. J Arthroplasty 1989;4:245-51

16. Kim YH. The results of a proximally-coated cementless femoral component in total hip replacement: a five- to 12-year follow-up. J Bone Joint Surg $[B r]$ 2008:90-B:299-305.
17. Kaplan EL, Meier P. Non parametric estimation from incomplete observations. J Am Stat Assoc 1958; 53:457-81

18. DeLee JG, Charnley J. Radiographic demarcation of cemented sockets in total hip replacement. Clin Orthop 1976;121:20-32.

19. Lachiewicz PF, Soileau ES, Bryant P. Second-generation proximally coated titanium femoral component: minimum 7-year results. Clin Orthop 2007;465:117-21.

20. Kim YH, Kim BJ, Ko HS, et al. Total hip reconstruction in the anatomically distorted hip: cemented versus hybrid total hip arthroplasty. Arch Orthop Trauma Surg 1998;117:8-14.

21. Chiavetta JB, Parvizi J, Shaughnessy WJ, Cabanela ME. Total hip arthroplasty in patients with dwarfism. J Bone Joint Surg [Am] 2004;86-A:298-304.

22. Inao S, Matsuno T. Cemented total hip arthroplasty with autogenous acetabular bone grafting for hips with developmental dysplasia in adults: the results at a minimum of ten years. J Bone Joint Surg [Br] 2000;82-B:375-7.

23. Biant LC, Bruce WJ, Assini JB, Walker PM, Walsh WR. Primary total hip arthroplasty in severe developmental dysplasia of the hip: ten-year results using a cementless modular stem. J Arthroplasty 2009;24:27-32.

24. Shinar AA, Harris WH. Bulk structural autogenous grafts and allografts for reconstruction of the acetabulum in total hip arthroplasty: sixteen-year-average follow-up. J Bone Joint Surg [Am] 1997;79-A:159-68.

25. de Kam DC, Gardeniers JW, Hendriks JC, Veth RP, Schreurs BW. Cemented polyethylene cups in patients younger than 40 years. Clin Orthop 2009;467:1753-64.

26. D'Antonio JA, Sutton K. Ceramic materials as bearing surfaces for total hip arthroplasty. J Am Acad Orthop Surg 2009;17:63-8.

27. Jacobs JJ, Urban RM, Hallab NJ, et al. Metal-on-metal bearing surfaces. J Am Acad Orthop Surg 2009;17:69-76.

28. McCalden RW. MacDonald SJ, Rorabeck CH, et al. Wear rate of highly crosslinked polyethylene in total hip arthroplasty: a randomized controlled trial. J Bone Joint Surg [Am] 2009;91-A:773-82.

29. Bragdon CR, Kwon YM, Geller JA, et al. Minimum 6-year followup of highly cross-linked polyethylene in THA. Clin Orthop 2007;465:122-7.

30. Al Kaissi A, Ganger R, Klaushofer K, Rumpler M, Grill F. Achondroplasia manifesting as enchondromatosis and ossification of the spinal ligaments: a case report. J Med Case Reports 2008;2:263

31. Horton WA, Hood OJ, Machado MA, Ahmed S, Griffey ES. Abnormal ossification in thanatophoric dysplasia. Bone 1988;9:53-61.

32. Baird EO, Kang QK. Prophylaxis of heterotopic ossification: an updated review. J Orthop Surg Res 2009;4:12

33. Saudan M, Saudan P, Perneger T, et al. Celecoxib versus ibuprofen in the prevention of heterotopic ossification following total hip replacement: a prospective randomised trial. J Bone Joint Surg [Br] 2007;89-B:155-9.

34. Harris WH. Traumatic arthritis of the hip after dislocation and acetabular fractures: treatment by mold arthroplasty: an end-result study using a new method of result evaluation. J Bone Joint Surg [Am] 1969;51-A:737-55. 